\title{
Binding of human serum proteins to Plasmodium falciparum-infected erythrocytes and its association with malaria clinical presentation
}

\author{
Mary Lopez-Perez ${ }^{1 *} \mathbb{D}$, William van der Puije ${ }^{2,3,4}$, Filip C. Castberg ${ }^{4}$, Michael F. Ofori ${ }^{2}$ and Lars Hviid ${ }^{1,4^{*}}$
}

\begin{abstract}
Background: The pathogenesis of Plasmodium falciparum malaria is related to the ability of parasite-infected erythrocytes (IEs) to adhere to the vascular endothelium (cytoadhesion/sequestration) or to surrounding uninfected erythrocytes (rosetting). Both processes are mediated by the expression of members of the clonally variant PfEMP1 parasite protein family on the surface of the IEs. Recent evidence obtained with laboratory-adapted clones indicates that $P$. falciparum can exploit human serum factors, such as $\lg M$ and $a_{2}$-macroglobulin $\left(a_{2} M\right)$, to increase the avidity of PfEMP1-mediated binding to erythrocyte receptors, as well as to evade host PfEMP1-specific immune responses. It has remained unclear whether PfEMP1 variants present in field isolates share these characteristics, and whether they are associated with clinical malaria severity. These issues were investigated here.
\end{abstract}

Methods: Children 1-12 years reporting with P. falciparum malaria to Hohoe Municipal Hospital, Ghana were enrolled in the study. Parasites from children with uncomplicated (UM) and severe malaria (SM) were collected. Binding of $\mathrm{a}_{2} \mathrm{M}$ and IgM from non-immune individuals to erythrocytes infected by P. falciparum isolates from 34 children (UM and SM) were analysed by flow cytometry. Rosetting in the presence of $\operatorname{lgM}$ or $\mathrm{a}_{2} \mathrm{M}$ was also evaluated. Experimental results were analysed according to the clinical presentation of the patients.

Results: Clinical data from 108 children classified as UM $(n=54)$ and SM cases $(n=54)$ were analysed. Prostration, severe malaria anaemia, and hyperparasitaemia were the most frequent complications. Three children were diagnosed with cerebral malaria, and one child died. Parasite isolates from UM $(n=14)$ and SM $(n=20)$ children were analysed. Most of the field isolates bound non-immune $\operatorname{lgM}(33 / 34)$, whereas the $\mathrm{a}_{2} \mathrm{M}$-binding was less common (23/34). Binding of both non-immune IgM and $\mathrm{a}_{2} \mathrm{M}$ was higher but not significant in IEs from children with SM than from children with UM. In combination, IgM and $\mathrm{a}_{2} \mathrm{M}$ supported rosette formation at levels similar to that observed in the presence of $10 \%$ human serum.

Conclusions: The results support the hypothesis that binding of non-immune $\lg \mathrm{M}$ and/or $\mathrm{a}_{2} \mathrm{M}$ to IEs facilitates rosette formation and perhaps contributes to P. falciparum malaria severity.

Keywords: $a_{2}$-Macroglobulin, Ghana, Malaria, Non-specific IgM, PfEMP1, Plasmodium falciparum, Rosetting, Severe malaria

\footnotetext{
*Correspondence: mlopez@sund.ku.dk; Ihviid@sund.ku.dk

${ }^{1}$ Centre for Medical Parasitology, Department of Immunology

and Microbiology, Faculty of Health and Medical Sciences, University

of Copenhagen, Copenhagen, Denmark

Full list of author information is available at the end of the article
}

\section{Background}

Malaria continues to be an important public health problem in the developing world. Despite intensive global efforts, the number of malaria cases worldwide has not

c) The Author(s) 2020. This article is licensed under a Creative Commons Attribution 4.0 International License, which permits use, sharing, adaptation, distribution and reproduction in any medium or format, as long as you give appropriate credit to the original author(s) and the source, provide a link to the Creative Commons licence, and indicate if changes were made. The images or other third party material in this article are included in the article's Creative Commons licence, unless indicated otherwise in a credit line to the material. If material is not included in the article's Creative Commons licence and your intended use is not permitted by statutory regulation or exceeds the permitted use, you will need to obtain permission directly from the copyright holder. To view a copy of this licence, visit http://creativeco mmons.org/licenses/by/4.0/. The Creative Commons Public Domain Dedication waiver (http://creativecommons.org/publicdomain/ zero/1.0/) applies to the data made available in this article, unless otherwise stated in a credit line to the data. 
changed for the past 4 years. In 2018, an estimated 228 million cases of malaria and 405,000 deaths occurred worldwide, most of them in Africa. Notably, 67\% of global deaths occurred in children aged under 5 years [1]. The broad spectrum of malaria-related manifestations ranges from asymptomatic parasitaemia to severe, life-threatening disease. Of the species infecting humans, Plasmodium falciparum is responsible for the vast majority of clinical cases as well as for almost all severe morbidity and mortality [1].

The pathogenesis of $P$. falciparum malaria is in part related to adhesion of parasite-infected erythrocytes (IEs) to the vascular endothelium (cytoadhesion/sequestration) in various tissues [2,3] or to surrounding, uninfected erythrocytes (rosetting) [4, 5]. Sequestration prevents the IEs destruction in the spleen [6], but can cause tissue inflammation and organ-specific complications $[7,8]$. In both, cytoadhesion and rosetting, the IEs bind to host cell membrane receptors via a diverse family of parasite-encoded protein ligands called P. falciparum erythrocyte membrane protein 1 (PfEMP1) $[9,10]$. These proteins are displayed on multi-protein complexes ("knobs") protruding from the IE surface [11]. Each parasite genome contains $\sim 60$ PfEMP1-encoding var genes $[12,13]$, but only a single PfEMP1 variant at a time is expressed on the surface of a given IE due to allelic exclusion [14]. However, the parasites can switch transcription among the different var genes to evade acquired PfEMP1specific immunity. The set of var genes varies substantially among $P$. falciparum genomes, creating a vast global repertoire of PfEMP1 proteins. PfEMP1 variants mediating formation of rosettes also bind to endothelial cells via distinct receptor-ligand interactions [15]. The receptor specificity is facilitated by the PfEMP1 secondary structure, with defined domains mediating distinct cytoadhesion phenotypes, which in turn have been associated with discrete clinical presentations [9]. This family of proteins mediate IE adhesion to a range of host receptors, including CD36 [16], intercellular adhesion molecule 1 (ICAM-1) [17, 18], endothelial protein $C$ receptor (EPCR) [18, 19], gC1qR [20], and oncofetal chondroitin sulfate (a.k.a. CSA) [21].

PfEMP1 also binds soluble plasma factors. Several PfEMP1 variants can bind IgM via the $\mathrm{F} c \mu$ region of the antibody rather than by the hypervariable, antigenspecific Fab fragment [22-24]. This type of IgM binding is sometimes called "non-immune". Recently, was documented that non-immune IgM-binding PfEMP1 proteins are frequent in $P$. falciparum laboratory clones $[24,25]$, and that $\alpha_{2}$-macroglobulin $\left(\alpha_{2} M\right)$, another abundant serum protein, also binds to PfEMP1 [26]. Whether PfEMP1 variants present in field isolates share these binding characteristics, and whether those features are associated with the clinical presentation of malaria are unknown. Therefore, the non-immune $\operatorname{IgM}$ and $\alpha_{2} \mathrm{M}$ binding was analysed in parasites from Ghanaian children with uncomplicated and severe malaria.

\section{Methods \\ Ethical statement}

The study was approved by the Noguchi Memorial Institute for Medical Research Institutional Review Board (NMIMR STC Number: STC Paper 5(1) 2013-2014) and by the Ethical Review Committee of the Ghana Health Service (026/13-14). Declaration of free willingness to participate in the study and written informed consent was obtained from parents/guardians of all study participants prior to enrolment.

\section{Study area}

This study was carried out within the frame of a broader study aimed at building malaria vaccine research capacity in Ghana (MAVARECA https://mavareca.ku.dk/). The participants were enrolled in Hohoe, a town located in the Volta Region about $220 \mathrm{~km}$ northeast of Accra. Malaria transmission intensity in the area is high with approximately 65 infectious bites per person per year and has two seasonal peaks, a major one in April-July and a minor one in September-November [27].

\section{Study participants and laboratory tests}

Children 1-12 years of age and reporting with P. falciparum malaria to Hohoe Municipal Hospital were enrolled in the study between July-August 2016. A sample size of 96 children was calculated based on 40,092 malaria cases confirmed at the Hohoe Municipal hospital in 2014 [28], using a level of confidence of $95 \%$, sampling error of $10 \%$, and $50 \%$ expected prevalence for IgM or $\alpha_{2} M$ binding. After enrolment, a project nurse and a physician completed a standardized questionnaire and performed a clinical examination. Severe malaria (SM) was defined according to the WHO criteria [29], and children were treated with artemether-lumefantrine or quinine IV as required. Venous blood samples were taken on the day of admission to determine haemoglobin levels ( $\mathrm{Hb}), \mathrm{ABO}$ blood group, and for research purposes. Samples were taken daily during the hospitalization and 1 week after initial presentation to assess haemoglobin levels and parasitaemia. Sickle cell $\mathrm{Hb}$ phenotype was determined by electrophoresis and glucose-6-phosphate dehydrogenase (G6PDH) deficiency tested by methylene blue reduction test [30].

\section{Field isolates and in vitro culture}

After removal of plasma, the pellet containing IEs was washed twice in RPMI 1640 medium (Sigma-Aldrich, 
Germany) supplemented with $50 \mu \mathrm{g} / \mathrm{mL}$ gentamicin (Sigma-Aldrich, Germany). A $100 \mu \mathrm{L}$ aliquot of the pellet was placed in RPMI 1640 medium supplemented with 0.5\% AlbuMAX II (Gibco-Life Technologies, Denmark), $2 \%$ heat-inactivated normal human serum (NHS), $2 \mathrm{mM}$ glutamine (Sigma-Aldrich, Germany), and $50 \mu \mathrm{g} / \mathrm{mL}$ gentamicin (referred to as $2 \%$ complete culture medium) before culturing at $2 \%$ haematocrit. The parasites were incubated at $37{ }^{\circ} \mathrm{C}$ in $2 \% \mathrm{O}_{2}, 5 \% \mathrm{CO}_{2}$, and $93 \% \mathrm{~N}_{2}$ atmosphere, before carrying out rosetting assays.

The rest of the washed pellet was gently mixed with glycerol freezing solution, aliquoted into cryotubes, and transferred to liquid nitrogen for long-term storage. Frozen samples were shipped to the University of Copenhagen, where they were thawed by standard methods before starting short-term in vitro cultures [31]. Briefly, the parasites were placed in $2 \%$ complete culture medium at $2 \%$ haematocrit and incubated at $37{ }^{\circ} \mathrm{C}$ in $2 \% \mathrm{O}_{2}, 5 \%$ $\mathrm{CO}_{2}$, and $93 \% \mathrm{~N}_{2}$ atmosphere. Parasitaemia was checked daily by Giemsa-stained thin smears and those with normal morphology that matured to the late-trophozoite stage were included in the study. The day before use in experiments including serum proteins, the parasites were transferred to serum-free RPMI 1640 medium $(0.5 \%$ AlbuMAX II).

\section{Rosetting assays}

The rosetting of fresh isolates was assessed in the first cycle of in vitro growth when the majority of the parasites had reached the trophozoite-late stage. After staining the parasites with $7 \mu \mathrm{g} / \mathrm{mL}$ of ethidium bromide for $2 \mathrm{~min}$, the percentage of rosettes was assessed by counting 200 ethidium bromide-stained IEs, using wet preparations and fluorescence microscopy. Rosettes were defined as IEs having two or more adhering uninfected erythrocytes.

To determine the role of non-immune IgM and $\alpha_{2} M$ binding in rosetting, short-term in vitro cultures of thawed cryostabilates were used. Late trophozoite stage IEs at $2 \%$ haematocrit in serum-free RPMI 1640 medium were incubated $1 \mathrm{~h}$ at $37{ }^{\circ} \mathrm{C}$ in $2 \% \mathrm{O}_{2}, 5 \% \mathrm{CO}_{2}$, and $93 \%$ $\mathrm{N}_{2}$ atmosphere with $10 \% \mathrm{NHS}$, or with $10 \mathrm{nM}$ IgM (Sigma-Aldrich, Germany), $10 \mathrm{nM} \alpha_{2} \mathrm{M}$ (Sigma-Aldrich, Germany), or both. The percentage of rosettes was assessed as described above.

\section{Measurements of non-immune $\lg M$ and $a_{2} M$ binding to PfEMP1}

Non-immune IgM and $\alpha_{2} M$ binding to IEs was detected by flow cytometry as previously described [24, 26, 32]. Binding of both proteins at $10 \mathrm{nM}$ has been detected in several laboratory clones [23-26], but included two additional concentrations ( $1 \mathrm{nM}$ and $100 \mathrm{nM}$ ) to explore the potential binding in the field isolates. Briefly, intact and unfixed late trophozoite stage IEs purified by magnetactivated cell sorting (MACS) were incubated with either 1,10 , or $100 \mathrm{nM}$ non-immune human IgM or $\alpha_{2} \mathrm{M}$ in PBS supplemented with $1 \%$ Ig-free bovine serum albumin (PBS 1\% BSA). IE-bound IgM was measured with a FITCconjugated anti-human IgM (1:150; Sigma), whereas $\alpha_{2} \mathrm{M}$ was determined with a combination of goat polyclonal anti-human $\alpha_{2} \mathrm{M}$ (1:300; Abcam, UK) and FITC-conjugated anti-goat IgG (1:150; Vector, UK). Non-immune IgM and $\alpha_{2} \mathrm{M}$ binding to IEs was quantified as the median fluorescence intensity (MFI) in IEs labelled with $10 \mu \mathrm{g} /$ $\mathrm{mL}$ Hoechst. BD LSR II flow cytometer was used for data acquisition and FlowLogic software (Inivai Technologies, Australia) for data analysis.

\section{Statistical analysis}

Data were analysed and plotted using IBM SPSS Statistics for Macintosh, Version 26.0 (IBM Corp) and GraphPad Prism version 8.0 (GraphPad Software, San Diego, California, USA), respectively. Nominal variables were analysed using descriptive statistics. The Mann-Whitney U or Friedman test and Kruskal-Wallis test followed by Dunn's multiple comparison test were used to compare two and more-than-two groups, respectively. Spearman's rank correlation $\left(r_{s}\right)$ was used to assess the correlation between numeric variables. Fisher's exact test was used to compare proportions. Any $p$-value $<0.05$ was considered statistically significant.

Multiple linear regression models were used to evaluate the effect of potential confounders on the relationship between percentage of rosettes or protein binding (dependent variables) and relevant independent factors. Models were adjusted by clinical category (UM and SM), age, parasitaemia, haemoglobin levels at admission, ABO blood group, and days of sickness.

\section{Results \\ Demographic and epidemiological characteristics}

A total of 113 patients were recruited to participate in the study. Five patients were excluded from the analysis because incomplete records did not allow clinical classification. The analysis presented here includes 108 children classified either as UM $(n=54)$ or SM $(n=54)$. Overall, a similar proportion of male and female were enrolled (1.1 to 1 ), with a mean age of 5 years (median: 5 years; interquartile range (IQR): 3-7 years). Most children presented at the hospital within a few days after onset of symptoms (median: 3 days; IQR 2-4 days), although some (22\%) reported after 5-22 days of sickness. Most of the children were admitted to the hospital (86\%), where they stayed less than 8 days (median: 2 days; IQR: $1-3$ days). The parasitaemia at admission and before anti-malarial 
treatment was determined in 87 children (81\%). Most (71\%) presented with $>10,000$ parasites $/ \mu \mathrm{L}$ (median: 37,367 parasites $/ \mu \mathrm{L} ;$ IQR: $857-95,822$ parasites $/ \mu \mathrm{L})$. Anaemia $(\mathrm{Hb}<11 \mathrm{~g} / \mathrm{dL})$ and severe anaemia $(\mathrm{Hb}<5 \mathrm{~g} /$ $\mathrm{dL}$ ) were observed in $69 \%$ and $8 \%$ of the children, respectively. On day seven post-admission, $83 \%$ of the children had anaemia, but none of them had severe anaemia. Sixteen SM children received blood transfusion.

Some demographic and clinical variables differed between children with UM and SM (Table 1). An additional diagnosis at admission was more frequent in SM than in UM. Acute tonsillitis, gastroenteritis, and respiratory tract infections were the most frequent in both groups. Twenty-one SM children had only one criterion for classification (Fig. 1). Cerebral malaria was observed in three children; it and was the only criterion in two of them. Neither severe bleeding nor pulmonary oedema were registered. One death was reported 1 day after enrolment, in a child with clinical shock, prostration, and hyperparasitaemia.

\section{Rosetting ex vivo}

Rosetting was assessed in 61 fresh isolates. The remaining samples $(n=47)$ were excluded either because the parasites failed to mature beyond ring stage in vitro or because the parasitaemia was too low for reliable assessment. Besides technical issues in the field with samples processing, a probable explanation is that children had taken anti-malarial drugs, and the parasites did not thrive overnight. Indeed, 23 out the 108 children reported taking anti-malarial drugs prior to admission (Table 1).
Although most of the field isolates formed rosettes (79\%), the percentage of rosettes was low (median: 7\%; range 2-64\%) and not different between children with UM and SM (Fig. 2). However, the percentage of rosettes was negatively correlated with age $\left(\mathrm{r}_{\mathrm{s}}=-0.373 ; 95 \% \mathrm{CI}-0.577\right.$ to $-0.128 ; p=0.003$ ), even after adjusting for potential confounders such as clinical category, parasitaemia, and ABO blood group $(\beta=-0.352 ; p=0.013)$.

\section{IgM- and $a_{2} M$-binding frequencies in UM and SM}

Thirty-nine frozen parasite samples were thawed and put into short-term culture, with $87 \%$ successful recovery. After one to three cycles, late trophozoite stage IEs from 34 children were purified and used to evaluate binding of non-immune human IgM and $\alpha_{2} \mathrm{M}$ by flow cytometry. Most of the field isolates bound non-immune IgM (33/34), and the binding was dependent of the concentration ( $\mathrm{p}<0.0001$; Friedman test). In contrast, the $\alpha_{2} \mathrm{M}$ binding was less common than IgM $(23 / 34 ; p=0.003$, Fisher's exact test), without significant effect of increasing the concentration $(\mathrm{p}=0.09$; Friedman test) (Fig. 3a). At $100 \mathrm{nM}$, both non-immune IgM and $\alpha_{2} \mathrm{M}$-binding correlated positively $\left(\mathrm{r}_{\mathrm{s}}=0.939 ; \mathrm{p}<0.001\right)$, and the association remained after adjusting for potential confounders such as clinical category, age, parasitaemia, haemoglobin levels at admission, and ABO blood group $(\beta=0.921 ; \mathrm{p}<0.001)$ (Fig. 2b).

The samples were separated into UM and SM to evaluate the association of serum protein binding with the clinical classification. At all concentrations, binding of non-immune IgM and $\alpha_{2} \mathrm{M}$ was higher in IEs from

Table 1 Demographic data and malaria history

\begin{tabular}{|c|c|c|c|c|c|}
\hline & \multicolumn{2}{|c|}{ UM $(n=54)$} & \multicolumn{2}{|c|}{$S M(n=54)$} & \multirow[t]{2}{*}{ p value $^{b}$} \\
\hline & Median & IQR & Median & IQR & \\
\hline Age (years) & 6 & $3-8$ & 4 & $2-6$ & 0.006 \\
\hline Days of hospitalization & 2 & $0-2$ & 3 & $2-4$ & $<0.0001$ \\
\hline Days of sickness & 3 & $2-4$ & 3 & $2-4$ & 0.91 \\
\hline Parasitaemia at admission ${ }^{a}$ & 20,336 & $11,751-35,192$ & 35,196 & $21,534-57,525$ & 0.15 \\
\hline Haemoglobin at admission & 10.7 & $10-12.2$ & 8.0 & $6-10.1$ & $<0.0001$ \\
\hline Frequencies & $\mathbf{n}$ & $\%$ & $\mathbf{n}$ & $\%$ & $p$ value ${ }^{b}$ \\
\hline Male/female & $34 / 20$ & $63 / 37$ & $23 / 31$ & $43 / 57$ & 0.05 \\
\hline Antimalarial preadmission & 9 & 16.7 & 14 & 25.9 & 0.35 \\
\hline Other diagnosis at admission & 17 & 31.5 & 35 & 64.8 & 0.001 \\
\hline Sickle cell Hb & 2 & 3.7 & 3 & 5.6 & 1.00 \\
\hline G6PDH deficiency ${ }^{c}$ & 8 & 14.8 & 8 & 14.8 & 1.00 \\
\hline
\end{tabular}

UM uncomplicated malaria, SM severe malaria, IQR interquartile range

a Geometric mean and $95 \% \mathrm{Cl}$ of geo. Mean

b $p$ value using Mann-Whitney test or Fisher's exact test between UM and SM, significant values are highlighted in italic

c Full or partial deficiency 


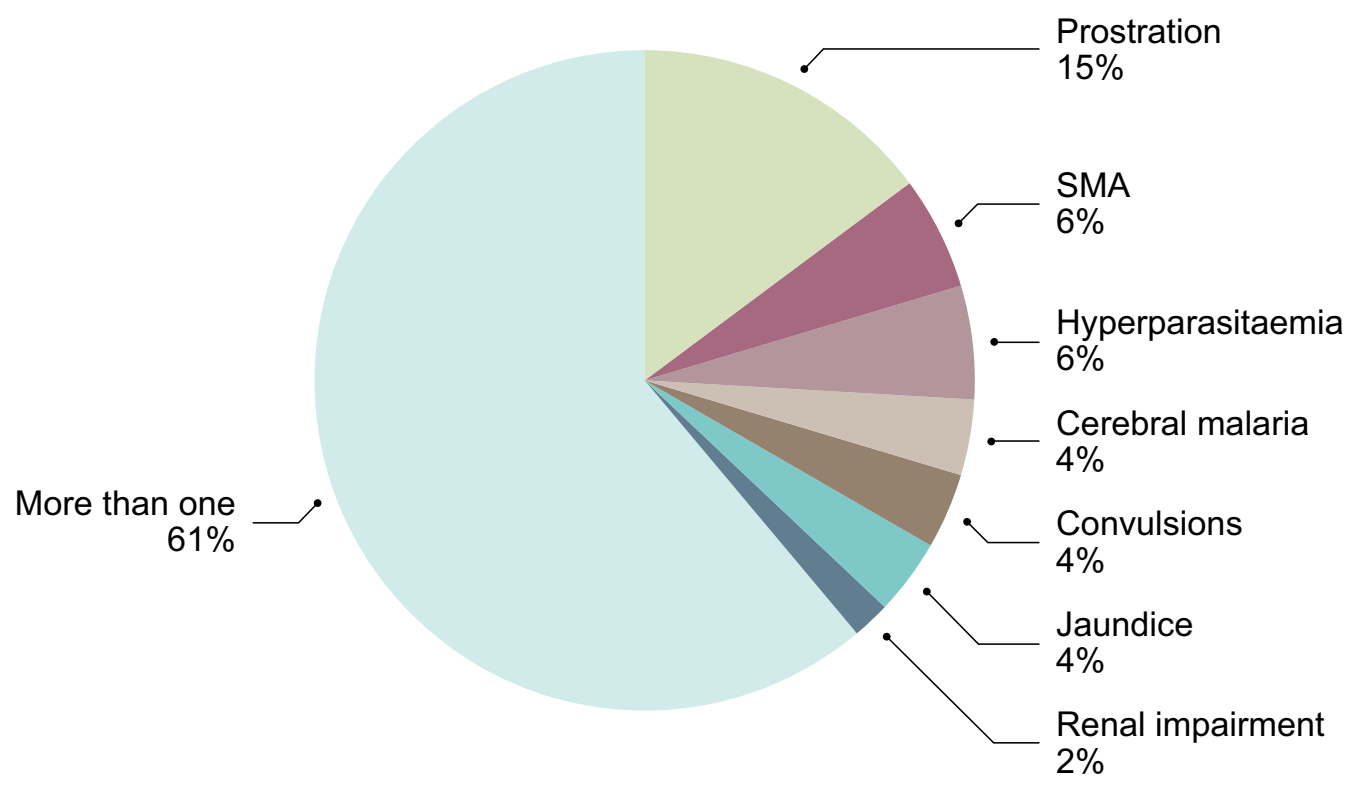

Fig. 1 Distribution of severe malaria subcategories. Children were classified as having a single or more than one criterion. SMA: severe malaria anaemia ( $\mathrm{Hb}<5 \mathrm{~g} / \mathrm{dL}$ ); hyperparasitaemia (> 10\%); cerebral malaria (coma with a Blantyre Coma Score $\leq 2)$; multiple convulsions without coma; jaundice (plasma bilirubin $>3 \mathrm{mg} / \mathrm{dL}$ ); renal impairment (creatinine $>3.0 \mathrm{mg} / \mathrm{mL}$ or urea $>20 \mathrm{mmol} / \mathrm{L}$ ). More than one criterion includes children with clinical shock ( $<70 \mathrm{~mm} \mathrm{Hg}$ ) and hypoglycaemia $(<40 \mathrm{mg} / \mathrm{dL})$

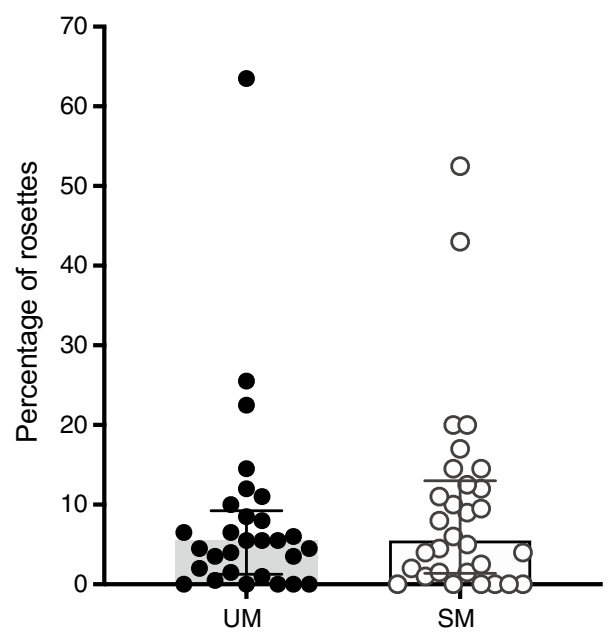

Fig. 2 Rosetting ex vivo. Rosettes were defined as IEs having two or more adherent uninfected erythrocytes. Medians and interquartile ranges are shown. $p=0.64$ between uncomplicated $(U M)$ and severe malaria (SM) using Mann-Whitney test

SM than from UM patients, although not significant at the chosen level of significance (Fig. 4). Non-immune IgM binding was negatively correlated with haemoglobin levels $\left(r_{s}=-0.411, p=0.016\right.$; and $r_{s}=-0.445$, $\mathrm{p}=0.009$ at 10 and $100 \mathrm{nM}$, respectively). The association was not significant after adjusting for age.

\section{$\lg \mathrm{M}$ and $\mathrm{a}_{2} \mathrm{M}$ support rosetting in the absence of human serum}

Rosetting is a highly variable phenotype, which in many cases depends on serum factors [33]. The impact of non-immune IgM and $\alpha_{2} \mathrm{M}$ on rosetting was evaluated in parasite field isolates after short in vitro culture of frozen samples. Rosetting did not occur or was very low in a serum-free culture medium $(0.5 \%$ AlbuMAX II), and addition of $10 \mathrm{nM}$ non-immune IgM to AlbuMAX medium had no effect. In contrast, the presence of $10 \mathrm{nM} \alpha_{2} \mathrm{M}$ supported rosette formation in some isolates, and in combination, IgM and $\alpha_{2} M$, supported rosette formation at levels similar to that observed in the presence of $10 \%$ human serum $(\mathrm{p}=0.86$, MannWhitney test). Further analysis according to the clinical classification, showed that the percentage of rosettes in the presence of both IgM and $\alpha_{2} M$, or NHS was higher, although not significantly, in parasites from SM children than from UM children $(p=0.36$ and $p=0.26$, respectively, Mann-Whitney test). In field isolates from SM but not UM, the percentage of rosettes using IgM plus $\alpha_{2} \mathrm{M}$ or NHS was significantly higher than the observed in AlbuMAX medium (Fig. 5). The combined effect of IgM plus $\alpha_{2} \mathrm{M}$ in rosetting appeared additive under the conditions used here, rather than the 

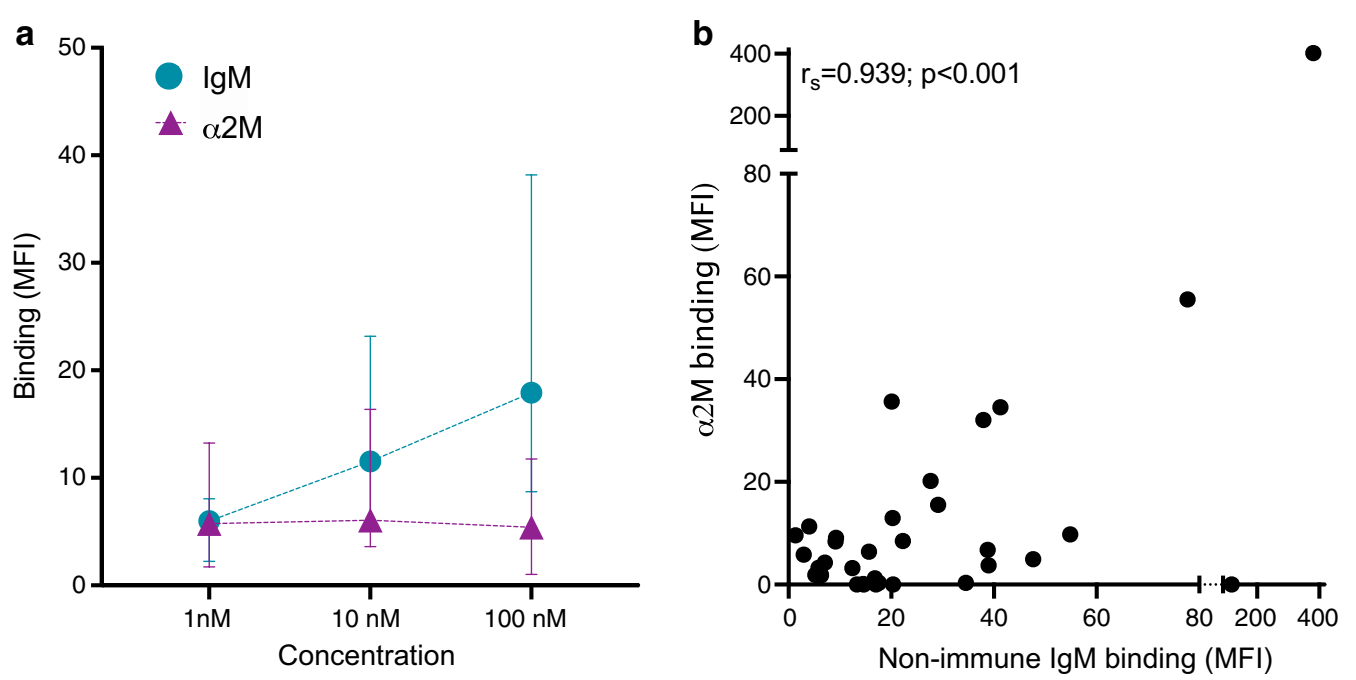

Fig. 3 Non-immune lgM- and $a_{2} M$-binding to $P$. falciparum-infected erythrocytes. a Binding of non-immune lgM (circles) and $a_{2} M$ (triangles) to IEs from 34 children. Medians and interquartile ranges are shown. $\mathbf{b}$ Correlation of non-immune IgM and $a_{2} M$-binding at $100 \mathrm{nM}$ to IEs ( $n=34$ ). Spearman's rank correlation $\left(r_{s}\right)$ and $p$ values are shown
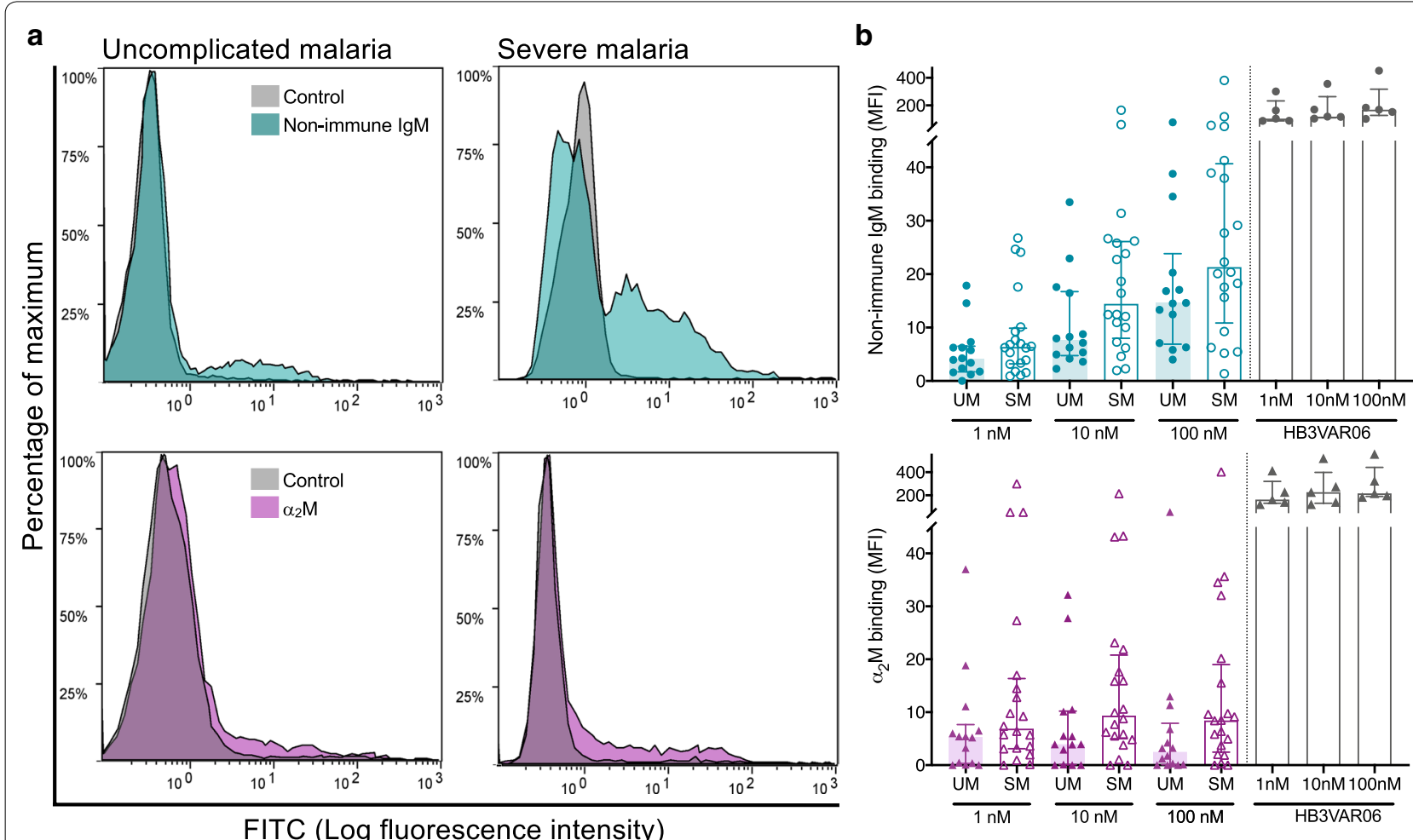

Fig. 4 Binding of non-immune $\lg M$ and $a_{2} M$ to $P$. falciparum-infected erythrocytes. a Representative flow cytometry histograms of field isolates from children with uncomplicated malaria (UM) and severe malaria (SM) in the presence of non-immune lgM (above) and $a_{2} M$ (below). $\mathbf{b}$ Binding of non-immune $\operatorname{lgM}$ (above) and $\mathrm{a}_{2} \mathrm{M}$ (below) to IEs from children with UM (closed symbols, $n=14$ ) and SM (open symbols, $\left.n=20\right)$ at $1 \mathrm{nM}(\mathrm{p}=0.24$ and $p=0.15), 10 \mathrm{nM}(p=0.07$ and $p=0.07)$, and $100 \mathrm{nM}(p=0.15$ and $p=0.06)$, respectively. A laboratory clone, HB3VAR06, it is included for comparison. Medians and interquartile ranges are shown. $p$ value between UM and SM using Mann-Whitney test. Two independent experiments were done at each concentration 

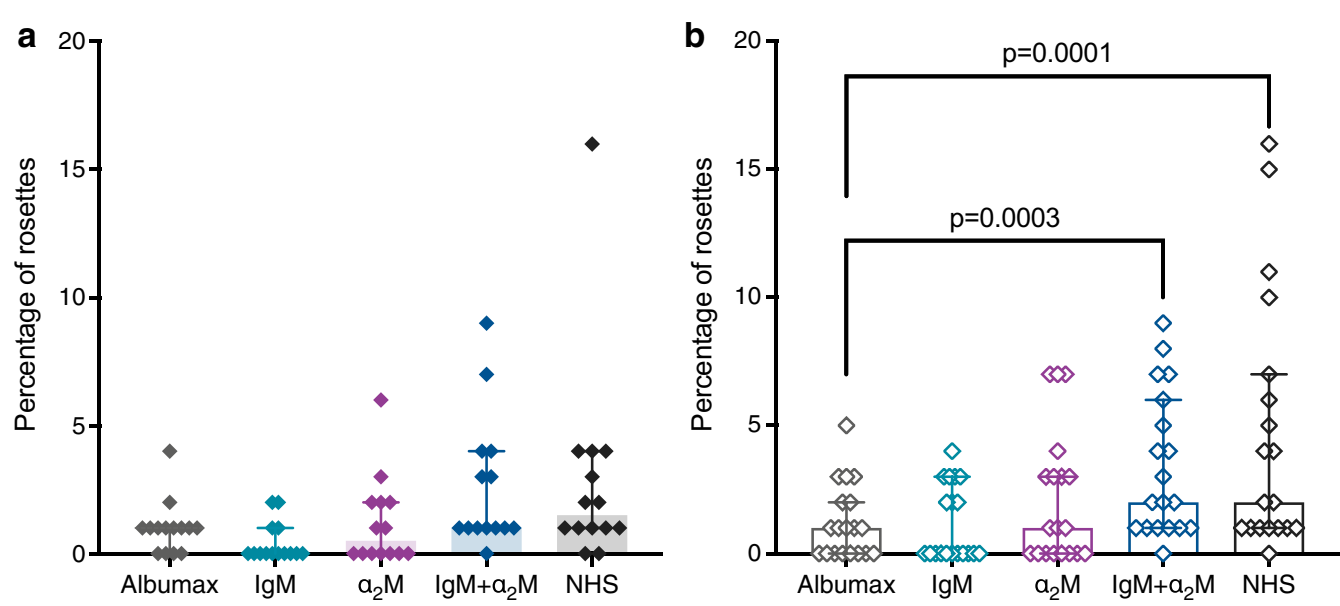

Fig. 5 Rosetting in P. falciparum-infected erythrocytes. Rosetting in the absence or presence of $10 \mathrm{nM}$ non-immune $\lg \mathrm{M}, 10 \mathrm{nM} \mathrm{a}_{2} \mathrm{M}$, or $10 \%$ normal human serum (NHS) in isolates from children with (a) uncomplicated (UM; closed symbols, $n=14$ ) or (b) severe malaria (SM; open symbols, $\mathrm{n}=20$ ). Medians, interquartile ranges, and $p$ values (Friedman test followed by Dunn's multiple comparisons test) are shown. For each experimental condition, two independent replicates were carried out

synergistic effect previously reported for a laboratory clone [26].

\section{Discussion}

The pathogenesis of $P$. falciparum malaria is related to the ability of the IEs to adhere to the vascular endothelium $[2,3]$ and to form rosettes $[4,5,34]$. Both processes are mediated by members of the PfEMP1 family proteins expressed on the IE surface $[9,10,12,13]$. Based on evidence obtained with parasite clones adapted to longterm in vitro culture and expressing a specific PfEMP1 variant, previously was hypothesized that $P$. falciparum exploits non-immune IgM to strengthen the low-affinity interactions of PfEMP1 with the carbohydrate receptors on uninfected erythrocytes in rosetting [23]. Moreover, IgM-binding PfEMP1 proteins are common in each of the three laboratory clones studied (3D7, HB3, and IT4/ FCR3) [24, 25], although not all of them mediated rosetting [24]. Similarly, $\alpha_{2} \mathrm{M}$ was identified as an important facilitator of rosetting that can bind at least four PfEMP1 molecules per $\alpha_{2} \mathrm{M}$ molecule, which might explain its effect on rosetting [26]. Remarkably, non-immune IgM and $\alpha_{2} \mathrm{M}$ appear to bind to the same domain in the laboratory clone HB3VAR06, where they synergistically facilitate rosetting [26].

To verify the above hypothesis, and assess its potential importance in $P$. falciparum malaria pathogenesis, the binding of non-immune IgM and $\alpha_{2} \mathrm{M}$ to erythrocytes infected by $P$. falciparum field isolates obtained from Ghanaian children with UM or SM was evaluated. Likewise, the rosetting in the presence of these serum proteins was tested. Using both approaches, it was found that PfEMP1 expressed on field isolate IEs can bind both non-immune IgM and $\alpha_{2} \mathrm{M}$, and that both proteins allow rosetting at similar levels observed in the presence of human serum. The data suggest that binding of non-immune IgM and $\alpha_{2} \mathrm{M}$ is higher in SM than in UM, consistent with a role for these phenotypes in malaria pathogenesis. However, additional studies are needed to validate this hypothesis further because the differences were not statistically significant. This may be related to the fact that cerebral malaria was scarce in the study area, combined with the particular role for rosetting in $\mathrm{CM}$ $[35,36]$.

That apart, it has to be acknowledged that most of the IgM-binding PfEMP1 proteins identified to date are encoded by var genes belonging to group B or Group C, which are commonly found in UM and asymptomatic infections [25]. Contrary to IgM-binding, which seems to be a frequent phenotype in laboratory clones [25], $\alpha_{2} \mathrm{M}$ binding is rare and restricted to DBL $\varepsilon$ and $\mathrm{DBL} \zeta$ domains (Lopez-Perez et al., unpublished data, [26]). Binding of $\alpha_{2} \mathrm{M}$ and non-immune IgM correlates in both field and laboratory isolates (Lopez-Perez et al., unpublished data), supporting the idea that both proteins bind to the same PfEMP1 variants. The dose-response effect observed with IgM, but not with $\alpha_{2} M$, it may be related to saturation. Each pentameric IgM molecule can bind two PfEMP1 molecules [23], whereas $\alpha_{2} M$ can bind at least four [26]. The few $\alpha_{2} \mathrm{M}$-binding variants to be expected among the heterogeneous PfEMP1 expressed by field isolates might easily be saturated.

The low ex vivo percentage of rosettes observed here, and the absence of the association with SM, may be 
related to the low number of children with cerebral malaria or severe anaemia $[35,36]$. Nevertheless, the percentage of rosettes were negatively correlated with age. This is consistent with the early in life acquisition of antibodies targeting PfEMP1 variants responsible for rosetting, thus facilitating the clearance of those IEs and contributing to protective immunity to SM. Indeed, an association between higher anti-rosetting activity and age was reported in Kenyan children [37]. The differences between the field isolates tested probably reflects the high degree of PfEMP1 diversity [38], with expression of several variants within a sample collected from a single individual in contrast with a single PfEMP1 variant in most of the laboratory clones. The IgM or $\alpha_{2} \mathrm{M}$ levels were not measured in the NHS used for the rosetting assays. However, has been reported that $\alpha_{2} \mathrm{M}$ levels in IgM-depleted serum is too low to support rosetting alone, and requires the presence of IgM for rosetting to occur [26].

\section{Conclusions}

The binding of $\alpha_{2} \mathrm{M}$ to IEs was uncommon, but both nonimmune IgM and $\alpha_{2} \mathrm{M}$-binding were slightly higher in IEs from children with SM than those with UM, although not significant at the chosen level of significance. Moreover, both proteins, $\alpha_{2} \mathrm{M}$ and IgM, appear to facilitate rosetting, particularly in isolates from children with SM.

\begin{abstract}
Abbreviations
$\mathrm{a}_{2} \mathrm{M}$ : $\mathrm{a}_{2}$-Macroglobulin; Hb: Haemoglobin; IgM: Immunoglobulin M; IEs: Infected erythrocytes; NHS: Normal human serum; PfEMP1: P. falciparum Erythrocyte membrane protein 1; UM: Uncomplicated malaria; SM: Severe malaria; WHO: World Health Organization.

\section{Acknowledgements}

We thank children and parents, health-care workers, and research staff involved in the field work in Ghana. We thank Maiken Visti and Kakra Dickson for technical assistance and the Core Facility for Flow Cytometry and Single Cell Analysis, Faculty of Health and Medical Sciences, University of Copenhagen.
\end{abstract}

\section{Authors' contributions \\ MLP and LH conceived and designed the study. WVP, FCC, MFO collected the clinical data and biological samples. WvP carried out the rosetting experi- ments in the field. MLP carried out the experiments and analysed the data. MLP and LH wrote the manuscript. All authors reviewed the manuscript. All authors read and approved the final manuscript.}

\section{Funding}

The field study was funded by the Danish International Development Agency, Danida (Grant 12-081RH) to LH. The experimental work was funded by the Lundbeck Foundation (R250-2017-1289) to MLP, and by the Danish Council for Independent Research (grant 4183-00539) and Danida (Grant 17-02-KU) to LH. The funders had no role in study design, data collection and analysis, decision to publish, or preparation of the manuscript.

\section{Availability of data and materials}

All data generated or analysed during this study are included within this article.

\section{Consent for publication}

All authors have given their consent for publication.

\section{Competing interests}

The authors declare no competing interests.

\section{Author details}

${ }^{1}$ Centre for Medical Parasitology, Department of Immunology and Microbiology, Faculty of Health and Medical Sciences, University of Copenhagen, Copenhagen, Denmark. ${ }^{2}$ Department of Immunology, Noguchi Memorial Institute for Medical Research, University of Ghana, Legon, Ghana. ${ }^{3}$ West African Centre for Cell Biology of Infectious Pathogens (WACCBIP), College of Basic and Applied Sciences, University of Ghana, Legon, Ghana. ${ }^{4}$ Centre for Medical Parasitology, Department of Infectious Diseases and Department of Clinical Microbiology, Rigshospitalet, Copenhagen, Denmark.

Received: 24 July 2020 Accepted: 1 October 2020

Published online: 08 October 2020

\section{References}

1. WHO. World malaria report 2019. Geneva: World Health Organization; 2019.

2. Miller LH, Baruch DI, Marsh K, Doumbo O. The pathogenic basis of malaria. Nature. 2002;415:673-9.

3. Miller LH. Distribution of mature trophozoites and schizonts of Plasmodium falciparum in the organs of Aotus trivirgatus, the night monkey. Am J Trop Med Hyg. 1969;18:860-5.

4. David PH, Handunnetti SM, Leech JH, Gamage P, Mendis KN. Rosetting: a new cytoadherence property of malaria-infected erythrocytes. Am J Trop Med Hyg. 1988;38:289-97.

5. Ho M, Davis TM, Silamut K, Bunnag D, White NJ. Rosette formation of Plasmodium falciparum-infected erythrocytes from patients with acute malaria. Infect Immun. 1991;59:2135-9.

6. David PH, Hommel M, Miller LH, Udeinya IJ, Oligino LD. Parasite sequestration in Plasmodium falciparum malaria: spleen and antibody modulation of cytoadherence of infected erythrocytes. Proc Natl Acad Sci USA. 1983;80:5075-9.

7. Dondorp AM, Ince C, Charunwatthana P, Hanson J, van Kuijen A, Faiz MA, et al. Direct in vivo assessment of microcirculatory dysfunction in severe falciparum malaria. J Infect Dis. 2008;197:79-84.

8. Taylor TE, Fu WJ, Carr RA, Whitten RO, Mueller JS, Fosiko NG, et al. Differentiating the pathologies of cerebral malaria by postmortem parasite counts. Nat Med. 2004;10:143-5.

9. Hviid L, Jensen AT. PfEMP1 - a parasite protein family of key importance in Plasmodium falciparum malaria immunity and pathogenesis. Adv Parasitol. 2015;88:51-84.

10. Smith JD, Chitnis CE, Craig AG, Roberts DJ, Hudson-Taylor DE, Peterson DS, et al. Switches in expression of Plasmodium falciparum var genes correlate with changes in antigenic and cytoadherent phenotypes of infected erythrocytes. Cell. 1995;82:101-10.

11. Kilejian A. Characterization of a protein correlated with the production of knob-like protrusions on membranes of erythrocytes infected with Plasmodium falciparum. Proc Natl Acad Sci USA. 1979;76:4650-3.

12. Rask TS, Hansen DA, Theander TG, Gorm Pedersen A, Lavstsen T. Plasmodium falciparum erythrocyte membrane protein 1 diversity in seven genomes-divide and conquer. PLoS Comput Biol. 2010;6:e1000933.

13. Su XZ, Heatwole VM, Wertheimer SP, Guinet F, Herrfeldt JA, Peterson DS, et al. The large diverse gene family var encodes proteins involved in cytoadherence and antigenic variation of Plasmodium falciparuminfected erythrocytes. Cell. 1995;82:89-100.

14. Deitsch KW, Calderwood MS, Wellems TE. Malaria. Cooperative silencing elements in var genes. Nature. 2001;412:875-6.

15. Adams Y, Kuhnrae P, Higgins MK, Ghumra A, Rowe JA. Rosetting Plasmodium falciparum-infected erythrocytes bind to human brain microvascular endothelial cells in vitro, demonstrating a dual adhesion phenotype mediated by distinct $P$. falciparum erythrocyte membrane protein 1 domains. Infect Immun. 2014;82:949-59.

16. Oquendo P, Hundt E, Lawler J, Seed B. CD36 directly mediates cytoadherence of Plasmodium falciparum parasitized erythrocytes. Cell. 1989;58:95-101. 
17. Berendt AR, Simmons DL, Tansey J, Newbold Cl, Marsh K. Intercellularadhesion molecule-1 is an endothelial-cell adhesion receptor for Plasmodium-falciparum. Nature. 1989;341:57-9.

18. Lennartz F, Adams Y, Bengtsson A, Olsen RW, Turner L, Ndam NT, et al. Structure-guided identification of a family of dual receptor-binding PfEMP1 that is associated with cerebral malaria. Cell Host Microbe. 2017;21:403-14.

19. Turner L, Lavstsen T, Berger SS, Wang CW, Petersen JE, Avril M, et al. Severe malaria is associated with parasite binding to endothelial protein C receptor. Nature. 2013;498:502-5.

20. Biswas AK, Hafiz A, Banerjee B, Kim KS, Datta K, Chitnis CE. Plasmodium falciparum uses gC1qR/HABP1/p32 as a receptor to bind to vascular endothelium and for platelet-mediated clumping. PLoS Pathog. 2007:3:1271-80.

21. Salanti A, Dahlback M, Turner L, Nielsen MA, Barfod L, Magistrado P, et al. Evidence for the involvement of VAR2CSA in pregnancy-associated malaria. J Exp Med. 2004;200:1197-203.

22. Pleass RJ, Moore SC, Stevenson L, Hviid L. Immunoglobulin M: restrainer of inflammation and mediator of immune evasion by Plasmodium falciparum malaria. Trends Parasitol. 2016:32:108-19.

23. Stevenson L, Huda P, Jeppesen A, Laursen E, Rowe JA, Craig A, et al. Investigating the function of Fc-specific binding of IgM to Plasmodium falciparum erythrocyte membrane protein 1 mediating erythrocyte rosetting. Cell Microbiol. 2015;17:819-31.

24. Jeppesen A, Ditlev SB, Soroka V, Stevenson L, Turner L, Dzikowski R, et al. Multiple Plasmodium falciparum Erythrocyte Membrane Protein 1 variants per genome can bind IgM via its Fc fragment FcH. Infect Immun. 2015;83:3972-81.

25. Quintana MDP, Ecklu-Mensah G, Tcherniuk SO, Ditlev SB, Oleinikov AV, Hviid L, et al. Comprehensive analysis of Fc-mediated lgM binding to the Plasmodium falciparum erythrocyte membrane protein 1 family in three parasite clones. Sci Rep. 2019;9:6050.

26. Stevenson L, Laursen E, Cowan GJ, Bandoh B, Barfod L, Cavanagh DR, et al. alpha2-macroglobulin can crosslink multiple Plasmodium falciparum Erythrocyte Membrane Protein 1 (PfEMP1) molecules and may facilitate adhesion of parasitized erythrocytes. PLoS Pathog. 2015;11:e1005022.

27. Kweku M, Liu D, Adjuik M, Binka F, Seidu M, Greenwood B, et al. Seasonal intermittent preventive treatment for the prevention of anaemia and malaria in Ghanaian children: a randomized, placebo controlled trial. PLoS ONE. 2008;3:e4000.
28. Kweku M, Takramah W, Takase M, Tarkang E, Adjuik M. Factors associated with malaria prevalence among children under five years in the hohoe municipality of ghana. J Transm Dis Immun. 2017;1:9.

29. WHO. Severe malaria. Trop Med Int Health. 2014;19(Suppl 1):7-131.

30. Gibbs WN. The methylene blue reduction test: evaluation of a screening method for glucose-6-phosphate dehydrogenase deficiency. Am J Trop Med Hyg. 1974;23:1197-202.

31. Cranmer SL, Magowan C, Liang J, Coppel RL, Cooke BM. An alternative to serum for cultivation of Plasmodium falciparum in vitro. Trans R Soc Trop Med Hyg. 1997;91:363-5.

32. Barfod L, Dalgaard MB, Pleman ST, Ofori MF, Pleass RJ, Hviid L. Evasion of immunity to Plasmodium falciparum malaria by lgM masking of protective lgG epitopes in infected erythrocyte surface-exposed PfEMP1. Proc Natl Acad Sci USA. 2011;108:12485-90

33. Mercereau-Puijalon O, Guillotte M, Vigan-Womas I. Rosetting in Plasmodium falciparum: a cytoadherence phenotype with multiple actors. Transfus Clin Biol. 2008;15:62-71.

34. Udomsangpetch R, Wahlin B, Carlson J, Berzins K, Torii M, Aikawa M, et al. Plasmodium falciparum-infected erythrocytes form spontaneous erythrocyte rosettes. J Exp Med. 1989;169:1835-40.

35. Carlson J, Helmby H, Hill AV, Brewster D, Greenwood BM, Wahlgren M. Human cerebral malaria: association with erythrocyte rosetting and lack of anti-rosetting antibodies. Lancet. 1990;336:1457-60.

36. Doumbo OK, Thera MA, Kone AK, Raza A, Tempest LJ, Lyke KE, et al. High levels of Plasmodium falciparum rosetting in all clinical forms of severe malaria in African children. Am J Trop Med Hyg. 2009;81:987-93.

37. Barragan A, Kremsner PG, Weiss W, Wahlgren M, Carlson J. Age-related buildup of humoral immunity against epitopes for rosette formation and agglutination in African areas of malaria endemicity. Infect Immun. 1998;66:4783-7.

38. Kamaliddin C, Rombaut D, Guillochon E, Royo J, Ezinmegnon S, Agbota G et al. From genomic to LC-MS/MS evidence: analysis of PfEMP1 in Benin malaria cases. PLoS ONE. 2019;14:e0218012.

\section{Publisher's Note}

Springer Nature remains neutral with regard to jurisdictional claims in published maps and institutional affiliations.
Ready to submit your research? Choose BMC and benefit from:

- fast, convenient online submission

- thorough peer review by experienced researchers in your field

- rapid publication on acceptance

- support for research data, including large and complex data types

- gold Open Access which fosters wider collaboration and increased citations

- maximum visibility for your research: over $100 \mathrm{M}$ website views per year

At BMC, research is always in progress.

Learn more biomedcentral.com/submissions 